\title{
An Assessment of the Size of Sella Turcica Among Adult Nigerians Resident in Lagos
}

\section{Ogunnaike Philip Olubunmi, Olatunji Sunday Yinka*, Owolabi Joshua Oladele, Ginigeme Anita Adimchukwunaka, Olanrewaju John Afees}

Department of Anatomy, Benjamin Carson Senior School of Medicine, Babcock University, Ilishan-Remo Nigeria

Email address:

poogunnaike@yahoo.com (Ogunnaike P. O.), adajosunday@yahoo.com (Olatunji S. Y.), olaowolabi001@yahoo.com (Owolabi J. O.), anita.ginigeme@yahoo.com (Ginigeme A. A.), olarewajuj@babcock.edu.ng (Olanrewaju J. A.)

${ }^{*}$ Corresponding author

\section{To cite this article:}

Ogunnaike Philip Olubunmi, Olatunji Sunday Yinka, Owolabi Joshua Oladele, Ginigeme Anita Adimchukwunaka, Olanrewaju John Afees. An Assessment of the Size of Sella Turcica Among Adult Nigerians Resident in Lagos. International Journal of Medical Imaging. Vol. 4, No. 3, 2016, pp. 12-16. doi: 10.11648/j.ijmi.20160403.11

Received: May 19, 2016; Accepted: June 2, 2016; Published: June 20, 2016

\begin{abstract}
One of the clinical significance of the sella turcica is the empty sella syndrome which is the condition of a shrunken or flattened pituitary gland; hence a familiarity with the sella turcica anatomy and radiological appearance is of great importance. The present study investigated the normal dimensions of the sella turcica and the relationship with gender and age in adult Nigerians resident in Lagos, using computed tomographs of patients who underwent CT head examination. This was carried out to determine if the dimensions of sella turcica vary with age, gender and race; this is with a view to providing normal, standard reference for the indigenous population in Nigeria. This study assessed: the length, the depth and the anteroposterior diameter of the sella turcica; 297 samples were obtained and analyzed using SPSS Windows Version 14.0. T- test was used for the statistical analysis and values obtained were expressed as mean \pm S.E.M. and $\mathrm{P}$ value $<0.05$ was considered statistically significant. The results showed the mean length of $9.81 \pm 0.094 \mathrm{~mm}$; the mean antero-posterior diameter of $11.37 \pm 0.090 \mathrm{~mm}$ and the mean depth of $8.49 \pm 0.08 \mathrm{~mm}$. It was also observed that neither the age group nor the gender of the patients is a determinant of the sella turcica dimensions. Furthermore, the males tend to have slightly larger sella turcica dimensions than the females and the values from the present study are lower than those reported in Caucasian studies. The size of pituitary gland can be roughly estimated from the dimensions of sella turcica obtained from radiological methods in pathological conditions since disease conditions of the "master gland" ultimately affect the size of the sella turcica.
\end{abstract}

Keywords: Sella Turcica, Tuberculm Sellae, Dorsum Sellae, Base of Pituitary Fossa

\section{Introduction}

The deformity of the sella turcica is often a major clue that an abnormality exists within the cranium, hence a familiarity with the sella turcica anatomy and radiological appearance is very important [1]. One of the clinical significance of the sella turcica is the empty sella syndrome which is the condition of a shrunken or flattened pituitary gland [2, 3].

The sella turcica also known as hypophyseal fossa is a saddle shaped depression in the body of the sphenoid bone in the human skull that houses the pituitary gland; it is a cephalometric landmark in the skull [4]. Anatomically, it is located in the sphenoid bone behind the chiasmatic groove and the tuberculum sellae situated within the middle cranial fossa [5] and on a lateral skull radiograph, the image of the sella turcica is U-shape.

Any abnormality of the pituitary gland could manifest from an altered shape of sella turcica, to disturbance in regulation of secretion of glandular hormones [6]. Also, a deviation from the normal size and shape of the sella turcica due to its malformation may be implicated in an undetected underlying disease [7] and it can be an indication of a pathological condition of the gland [8]. The anatomy of the sella turcica varies in size and shape; it has been classified into three types: round, oval and flat [9]. The floor of the sella turcica, which in most cases is concave, may be flat or 
even convex [10]. The sella turcica is usually demarcated by a dense, thin white line in lateral radiographs. It is sometimes more important to recognize this feature than to estimate the size of the fossa [11].

Many studies $[10,12,13]$ have reported several changes in the size of the sella turcica in various pathological conditions such as Down Syndrome, Williams syndrome, Seckel Syndrome and lumbosacral myeloneningocele. The present study which made use of lateral Computed Tomography images of the skull was undertaken to establish the normal dimensions of sella turcica in adult Nigerian population with a view to establish whether the normal size of the sella turcica truly does vary with age, gender and race. The sella turcica has not been investigated in the locality with the use of Computed Tomography and previous studies conducted on the dimension of the sella turcica made used of radiographical images. Also, it was observed that in both anatomical and clinical practice in Nigeria, data relating to the description of normal anatomical size of the sella turcica are based mostly on Caucasian studies. The result of this study will provide a base line data on the normal size of the sella turcica for the indigenous population, which could be of assistance in the evaluation and detection of pathological conditions of the sella turcica.

\section{Materials and Methods}

\subsection{Sample Population}

The study was carried out on all the available lateral computed tomographs of the skulls of adults retrieved from the archival room of the radiology departments of the Lagos University Teaching Hospital (LUTH) and Reddington Multispecialist Hospital, Ikeja, Lagos. A total of 297 samples (both males and females) were used for this study; two hundred and five (205) samples from LUTH and ninety-two (92) samples from Reddington hospital.

\subsection{Equipments and Accessories Used in Data Collection}

CT Scanner, Radiology CT Reports, Patient's Records, Radiology Information System Software and Normal, lateral CT images

\subsection{Method of Data Collection}

The following were retrieved from the patients' record: age, sex and biometric analysis of the sella turcica. CT scanned images were used for this study. Data collection was based on timeframe rather than age in order to have a large range of materials to work with.

\subsection{Measurement Technique}

The normal size of the sella turcica was measured by tracing the contour of the pituitary fossa from the tip of the dorsum sellae to the turberculum sellae and then following a straight line from the turberculum sellae back to the origin. This corresponds to the position of the diaphragmatic sellae [14].
The length of the sella turcica was measured as the distance from the turberculum sella to the tip of the dorsum sellae, and the depth of sella turcica was measured perpendicular to this line to the deepest point on the floor. The anterior-posterior greatest diameter of the sella is measured to a point on the posterior inner wall of the pituitary fossa furthest from the turberculumsellae [14].

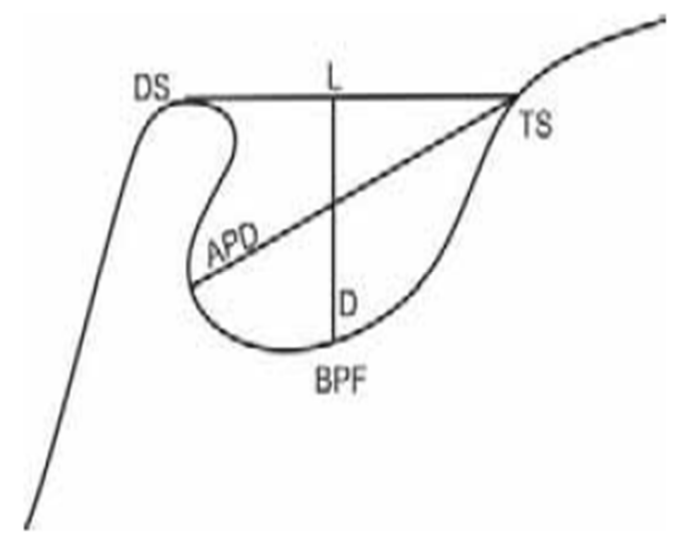

Figure 1. Illustration of Normal Sella turcica Morphology [14].

DS --- TS = the length (L)

APD--TS = Anterior posterior diameter (APD)

$\mathrm{L}$--- BPF $=$ Depth of the sella turcica (D)

Area of the sella turcica $=$ Length $\mathrm{x}$ Depth

$\mathrm{TS}=$ Turberculum Sellae, DS $=$ Dorsum Sellae, BPF $=$ Base of pituitary fossa

Figure 1 shows normal sella turcica morphology and reference lines used for measuring sella size. The DS-TS indicates the length of the sella turcica, APD_-TS indicates the diameter of the sella turcica, and L-BFP line indicates the depth of the sella turcica.

The method of measurement used in this research is that of Silverman [15].

According to Silverman [16] and Kisling [17], the following lines in the above diagram were measured to determine the size of the sella turcica; the reference lines used were situated in the midsagittal plane.

A) The Sella Turcica Length: Was obtained from measuring the distance from the tuberculum sellae (TS) to the tip of dorsum sellae (DS).

B) The Sella turcica Depth: Was obtained from measuring a perpendicular from the line mentioned above to the deepest point on the floor of the fossa; that is the base of the pituitary fossa (BPF).

C) The Antero-posterior Greatest Diameter of the Sella Turcica: Was obtained from measuring from the tuberculum sellae (TS) to the furthest point on the posterior inner wall of the fossa (SP), below the dorsum sellae.

\subsection{Inclusion and Exclusion Criteria}

The data that was collected included all the available lateral view computed tomography of the skull of healthy adult patients, starting from January 2014 to December 2015. Inclusion Criteria 
- Selection of CT images for the study was based on the following:

- Lateral view of computed tomography of the skull.

- Clear visualization and recognition of the dorsum sellae and tuberculum sellae.

- Only normal lateral computed tomographs of the skull were included.

- Only lateral skull CT images of Nigerians residing in Lagos were included.

Exclusion Criteria

- Every other view of the skull examination was excluded.

- Poor quality computed tomographs.

- Computed tomographs showing any obvious abnormal sella turcica.

- Computed tomographs of those patients not residing in Lagos.

\subsection{Statistical Analysis}

Data were analyzed using SPSS Windows Version 14.0 (SPSS Inc, IBM, UK). Descriptive statistics of Mean \pm Standard error of mean (S. E. M). were used to summarize the data obtained. Two-sided $\mathrm{P}$ values were calculated using the Paired sample T-test for observed variables. $\mathrm{P}$ values $<0.05$ were considered statistically significant.

\subsection{Ethical Consideration}

Ethical standard as prescribed in the declaration of Helsinki (2000) were duly observed.

\section{Results}

Table 1. Dimensions of the Sella turcica.

\begin{tabular}{llll}
\hline $\begin{array}{l}\text { Dimensions of Sella } \\
\text { Turcica }(\mathbf{m m})\end{array}$ & Length & AP diameter & Depth \\
\hline $\mathrm{N}$ & 297 & 297 & 297 \\
Mean \pm S.E.M & $9.81 \pm 0.094$ & $11.37 \pm 0.090$ & $8.49 \pm 0.081$ \\
\hline
\end{tabular}

The sella turcica dimensions are expressed as Mean \pm Standard Error of Mean. $\mathrm{N}=$ number of patients, AP Diameter $=$ Antero-posterior Diameter

Table 2. Relationship between Gender and Dimensions of Sella Turcica.

\begin{tabular}{lll}
\hline Gender & Male & Female \\
\hline $\mathrm{N}$ & 152 & 145 \\
Length $(\mathrm{mm}), \mathrm{M} \pm$ S.E.M & $9.88 \pm 0.131$ & $9.74 \pm 0.134$ \\
AP Diameter, $\mathrm{M} \pm$ S.E.M & $11.51 \pm 0.145$ & $11.24 \pm 0.144$ \\
Depth, $\mathrm{M} \pm$ S.E.M & $8.61 \pm 0.124$ & $8.37 \pm 0.107$ \\
\hline
\end{tabular}

The Relationship between Gender and Dimensions of Sella Turcica are expressed as Mean \pm Standard Error of Mean. $\mathrm{N}=$ number of patients, AP Diameter $=$ Antero-posterior Diameter.

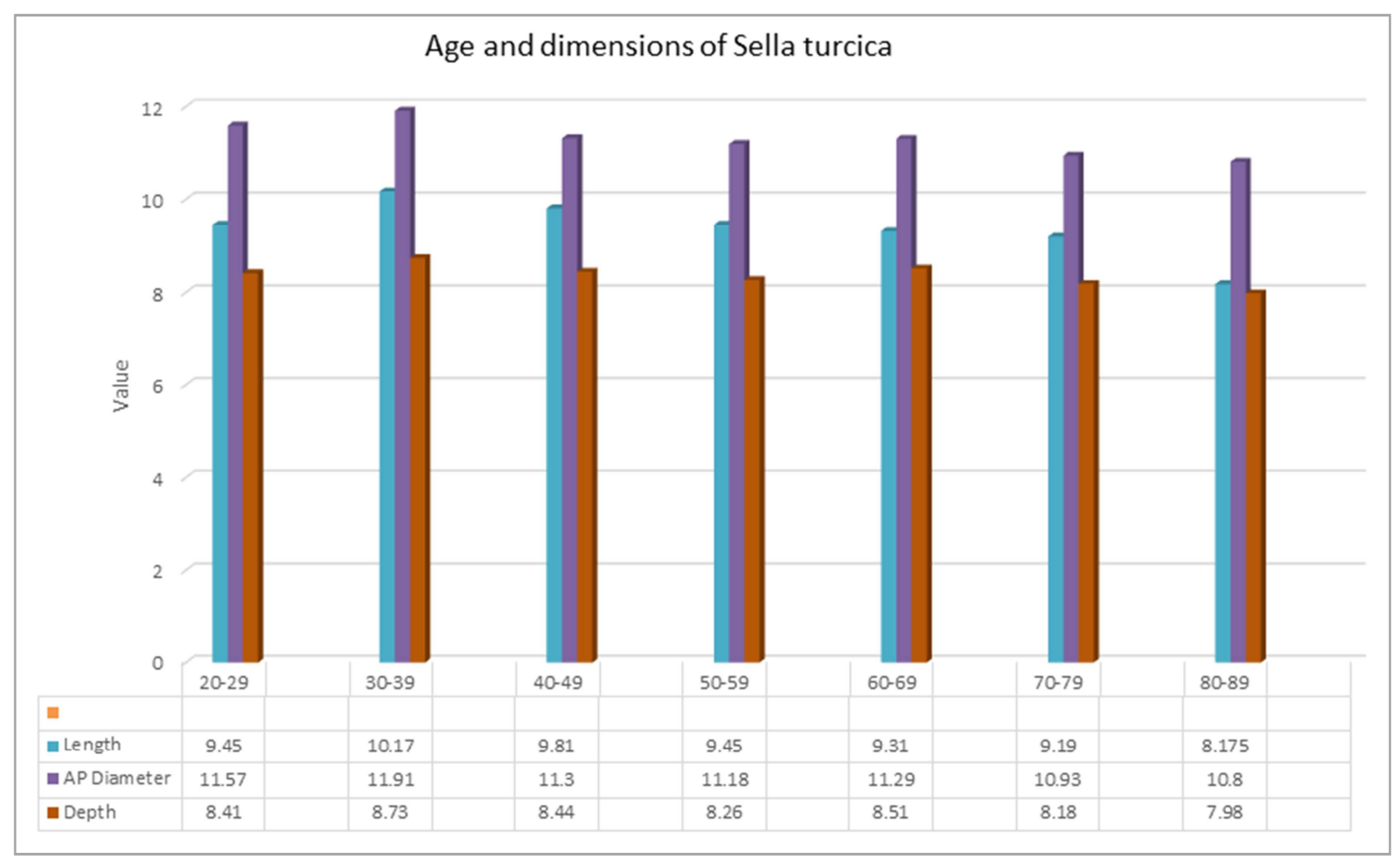

Figure 2. Showing the relationship between Age and Dimensions of Sella Turcica.

\section{Discussion}

The present study investigated the normal dimensions of the sella turcica and the relationship with gender and age in adult Nigerians resident in Lagos, using computed tomographs of patients who underwent CT head examination.

As showed in Table 1, 297 patients were used for this study and out of the whole population studied; the sella turcica has a mean length of $9.8 \mathrm{~mm}$, mean antero-posterior diameter of $11.37 \mathrm{~mm}$, and a mean depth of $8.5 \mathrm{~mm}$. Sella turcica dimensions reported by many researchers [11, 15] are based on Caucasian populations and the data were mostly obtained from skull radiographs. Based on our investigation, it was observed that, this is the first time the sella turcica was 
investigated on computed tomography in the indigenous population. Due to this major difference in the methodology, comparisons with other works should be done with caution.

Comparing the values from the present study with that of Zegga [18] who reported values to the length of $11.4 \mathrm{~mm}$, depth of $9.3 \mathrm{~mm}$ and antero-posterior diameter of $14.0 \mathrm{~mm}$; it is obvious that the values of this study are smaller compared to Zegga [18]. This difference could be due to the shortfall of the radiographic method. Similar pattern was noted by Asad and Hamid [19], who reported that the mean length of sella turcica in subjects of the De Montmorency College is $14.9 \mathrm{~mm}$, and Axelsson [20] who reported linear dimension (antero-posterior diameter) which is on average even larger than the values reported by Zegga [18]. This observed discrepancy in sella turcica values of Caucasian population and the Nigerian population can be partly attributed to the shortfall of the radiographic method - superimposition which was used in Zegga [18] and Asad and Hamid [19]. This study used the computed tomography which gives a more exact impression of anatomical features thereby avoiding this drawback associated with the radiographic method. The differences in values obtained in this research and that of Caucasian population could also be attributed to the difference in race.

Table 2, shows the relationship between the sella turcica dimensions and gender, though, there was no statistically significant difference between those values, it was observed that the males have values more than that of females across the three dimensions. This could be attributed to sexual dimorphism in form of thicker bones and prominent bony markings in the males compared to that of females and anatomical features of the human skull which tend to be larger in males than in females [21]. This is similar to the findings of Stefan [22] who reported that the length of the sella turcica was larger in males, while the depth and greatest diameter were almost similar for both sexes.

The relationships between the dimensions of the sella turcica across different age groups is presented in Figure 2; although there was no statistically significant relationship between the sella turcica values and age ranges, but there is an observable slight depreciation noted across all the sella dimensions as the age range increases. Therefore, age group of the patients may not a major determinant of the dimensions of sella turcica. This result is in consonance with others $[23,24$, 25] and in contrast to the study carried out by Valizadeh [26] who demonstrated that patients' age had a direct and significant correlation with the antero-posterior diameter of the sella turcica and by advances in age, the diameter of the sella turcica significantly increased as confirmed.

Furthermore, before the slight depreciation of sella dimensions as age increases, there is a sharp rise in sella AP diameter of individuals in their 20's which peaked in their $30 \mathrm{~s}$. In another sella turcica study of indigenous population done by Ize-Iyamu [27] in Benin City, Nigeria, the same observation was reported. This could be attributed to the fact that most individuals in this age group are at the peak of their lifetime physical and structural growth.
It is important to emphasize that the primary objective of this study was to provide reliable data on the normal dimensions of sella turcica for our indigenous Nigerians population. The clinical significance of studying the sellaturcica has been reinforced by the works of many researchers $[12,13]$ who reported that changes in size of the sella turcica are frequently related to pathology. Russell 11 concluded that the size and shape of sella turcica may be affected by pathological conditions such as Down syndrome, Williams syndrome, Seckel Syndrome and lumbosacral myeloneningocele and Meador [28] further associated hypopituitarism and dwarfism with small sella turcica dimensions.

\section{Conclusion}

In conclusion, it is evident from this study that computed tomography method has shown that the sella turcica has a mean length of $9.8 \mathrm{~mm}$, mean diameter of $11.37 \mathrm{~mm}$, and a mean depth of $8.5 \mathrm{~mm}$. The values reported in this research are lower than those reported in Caucasian studies. No significant difference in size of the sella turcica could be found between the age ranges and gender and the size of pituitary gland can be roughly estimated from the dimensions of sella turcica obtained from radiological methods in pathological conditions [29] since disease conditions of the "master gland" ultimately affect the size of the sella turcica. CT and MRI give more accurate values than radiographical method and in this regard, the sella turcica has a "largely constant dimensions" except in pathological conditions [30]. It is therefore recommended that further investigations should be carried out on the assessment of the possible correlations between sella turcica dimensions and head-skull cephalometric parameters and variations in sella turcica dimensions among the various ethnic groups.

\section{References}

[1] Meschan Isadore (1975). An Atlas of Anatomy Basic to Radiology. Published by Saunders (W. B.) Co Ltd, p 342-349.

[2] Tekiner, Halil; Acer, Niyazi; Kelestimur, Fahrettin (2014). "Sella turcica: an anatomical, endocrinological, and historical perspective". Pituitary 18 (4): 575-578.

[3] Agrawal JK, Sahay RK, Bhutada SK, Reddy VS, Agrawal NK. (2001) Empty sella syndrome. Indian Academy of Clinical Medicine; 2 (3): 198-202.

[4] Saokar, C. (2014). Assessment of Sella Turcica Morphology and Dimensions In An Indian Population. Indian Journal of Applied Research. 4 (10): 54-59.

[5] Mancall, Elliott L.; Brock, David G., eds. (2011). "Cranial Fossae". Gray's Clinical Anatomy. Elsevier Health Sciences. p. 154.

[6] Saokar, P. C., Sudhir, N. (2014). The Comparative Study of Size of Sella Turcica in Different Skeletal Types In Local Population -An In Vitro Study. Indian Journal of Applied (4) (10): 160-161. 
[7] Eman, A. A. (2007). The Shape and Size of Sella Turcica In Skeletal Class II and Class III Saudi Objects. Eur Jour. Orthod. Vol 29. 457-463.

[8] Bruneton, J. N., Drouillard, J. P., Sabatier, J. C., Elie, G. P., \& Travenir, J. F. (1979). Normal Variants of The Sella Turcica. Comparison of Plain Radiographs and Tomograms in 200 cases. Radiology. 131 (1): 99-104.

[9] Romans G. J. (1982). Cunningham's Manual of Practical Anatomy, Volume Three Head and Neck and Brain $14^{\text {th }}$ Ed. Oxford University Press.

[10] Camp, J. D. (2005). Normal and Pathological Anatomy of the Sella Turcica as Revealed by Roentgenograms. America Journal of Roentgenology. 12: 143-155.

[11] Russell, B. G., \& Kjaer, I. (2008). Postnatal Structure of Sella Turcica in Down Syndrome. American Journal of Medical Genetics. 87: 183-188.

[12] De Marinis. (2005). Imaging of Sella and Parasellar Disease. Seminars in Ultrasound, CT, and MRI. Radiology. 19: 257-271.

[13] Pisaneschi, M., \& Kapoor, G. (2005). Imaging the Sella and Parasellar Region. Neuroimaging Clin N Am. 15 (1): 203-19.

[14] Haritha, P. S., Vignesh, K., \& Arun, C. (2013). The Size and Morphology of Sella Turcica in Different Skeletal Patterns among South Indian Population: A Lateral Cephalometric Study. JP Journals. 47 (4): 266-271.

[15] Silverman, F. N. (1957). Roentgen Standards for Size of the Pituitary Fossa from Infancy through Adolescence. American Journal of Roentgenology. 78 (3): $451-60$.

[16] Silverman, F. N. (2000). Roentgen Standards for Size of Pituitary Fossa from Infancy Through Adolescence. American Journal of Roentgenology. 28: 451-460.

[17] Kisling, E., \& Copenhagen. (1966). Cranial Morphology in Down's Syndrome. A Comparative Roentgen Cephalometric Study in Adult Males. $6^{\text {th }}$ edition.

[18] Zegga, A. D., Ahmed, D., Tadros, A. A., Saidu, S. A. (1990). Description of The Normal Variants of The Anatomical Shapes of Sella Turcica. Radiology. 899 (7): 187-192.

[19] Asad, S., \& Hamid, W. (2005). Assessment and Comparisons of Dimensions of Sella TurcicaIn Skeletal Class I and Skeletal Class II Cases. Pak Oral Dental Journal. 25: 59-64.
[20] Axelsson S, Kjær I, Storhaug K (2004). Post-natal size and morphology of the sella turcica, Longitudinal cephalometric standards for Norwegians between 6 and 21 years of age. European Journal of Orthodontics 26: 597-604

[21] Chaurasia's B D. (2010). Human Anatomy: Regional and Applied, Dissection and Clinical. vol. 2, $5^{\text {th }}$ edition CBS Publishers, Thomas Press, New Delhi, India, p 1-466.

[22] Stefan Axelsson and Kari Storhaug (2004). Post-natal size and morphology of the sella turcica in Williams syndrome. European Journal of Orthdontics. Vol 26. 597-604.

[23] Melson, B. (1999). The Cranial Base: The Postnatal Development of The Cranial Base Studied Historical on Human Autopsy Material. Acra Odonto logica Scandi navica. 32 (62): 57-71.

[24] Choi, W. J., Hwang, E. H., \& Lee S. R. (2001). The Study of Shape and Size of Normal Sella Turcica in Cephalometric Radiographs. Korean Jour. Oral Maxillofacial Radiology. 31 (1): 43-49.

[25] Elster, A. D., Chen, M. Y., Williams, D. W., \& Key, L. L. (2006). Pituitary Gland. MR Imaging of Physiology Hypertrophy in Adolescence Radiology. 72: 754-761.

[26] Valizadeh, S., Shahrzad, S., Mohseni, S., Azimi, F., \& Bakhshandeh, H. (2015). Correlation of Shape and Size of Sella Turcica With the Type of Facial Skeleton Class in an Iranian Group. Iran J Radiol. 12 (3): e 16059.

[27] Ize-Iyamu, I. (2014). Sella Turcica Shape, Linear Dimensions, and Cervical Vertebrae Staging in Preorthodontic Patients in Benin City, Nigeria. Sahel Medical Journal. 17 (4): 151-158.

[28] Meador, C., \& Worrell, J. (1996). The Sella Turcica in Postpartum Pituitary Necrosis (Sheehan's Syndrome). Ann Intern Med. 65 (2): 259-264.

[29] Kucharczyk, W., \& Hazewinkel, M. (2008). Sella Turcica and Parasellar Region. Retrieved from Radiology Assistant. nl on 10/04/16.

[30] Melson, B. (1999). The Cranial Base: The Postnatal Development of The Cranial Base Studied Historical on Human Autopsy Material. Acra Odontologica Scandinavica. 32 (62): 57-71. 